\title{
Assessment of Knowledge and Physical Activity Pattern of Civil Servants in Ilorin South Local Government, Kwara State, Nigeria
}

\section{Adeoye Sikiru Adewale1*, Yusuf Naimat Aderonke², Abubakar Nurudeen $\mathbf{0 j o}^{3}$}

${ }_{1 *}$ Department of Human Kinetics Education, Faculty of Education, University of Ilorin, Ilorin, Kwara State, Nigeria

2Federal College of Education (Technical), Gusau, Zamfara State, Nigeria

${ }^{3}$ Kogi State University, Anyingba, Kogi State, Nigeria

\author{
Article History: \\ Received: 6 June 2021 \\ Accepted: 29 September 2021 \\ Published: 1 October 2021 \\ Keywords: \\ Regular Physical Activity, \\ Physical Activity Pattern, Civil \\ Servants, Participation
}

\begin{abstract}
If regular physical activity can be packaged into a pill, it will be the commonest drug on the counter. Therefore, this study assessed the knowledge and physical activity pattern of civil servants in Ilorin south Local Government, Kwara State, Nigeria. Descriptive research design of survey method was used for this study. The population for this study comprised civil servants in Ilorin South Local Government, Kwara State, Nigeria. Multi-stage probability sampling technique was conducted to select 259 respondents. Adapted GPAQ was used as instrument for data collection. The instrument was validated and tested for reliability. A correlation co-efficient of 0.84 was obtained through test re-test method using Pearson Product Moment Correlation. Socio-demographic data of the respondents was analysed using descriptive statistics of frequency, percentage, mean and standard deviation and to answer the research questions; inferential statistics of Pearson's Product Movement Correlation (PPMC), Oneway Analysis of variance (ANOVA) and independent sample t-test were used to test the null hypotheses at 0.05 significance. It was concluded in the study that there is significant relationship on Knowledge and pattern of physical activity of civil servants in Ilorin South Local Government Kwara State among others. Recommendation this study; experts in the field of physical activity and fitness in conjunction with the management of various ministries and commissions in the study locale should organise workshops and seminars to improve the knowledge of the civil servants on the benefits of regular participation in physical activity. Also, an official hour should be earmarked for staff to encourage participation by all.

How To Cite:

Adewale, A. S., Aderonke, Y. N., \& Ojo, A. N. (2021). Assessment of Knowledge and Physical Activity Pattern of Civil Servants in Ilorin South Local Government, Kwara State, Nigeria. Indonesian Journal of Sport Management, 1(2), 115-127. https://doi.org/10.31949/ijsm.v1i2.1129
\end{abstract}

Corresponding author: Adeoye, S. A, Department of Human Kinetics Education, Faculty of Email: sayhi2wale001@gmail.com 


\section{INTRODUCTION}

Advancement in medicine in the 21st century has reduced the risk of communicable diseases by producing vaccines and drugs that are effective in treating certain infectious diseases such as poliomyelitis, cholera, Tuberculosis among others. Therefore, this laudable achievement in medicine has helped humanity in reducing morbidity and mortality rate. The advancement witnessed in the present era is not limited to medical profession but also technology where virtually all human tasks can be performed using machines. The use of these modern machines, tools and devices to perform certain tasks have continued to render man physically inactive for most of the hours spent daily. Physical activity is defined as any bodily movement (physical exertions) produced by skeletal muscles contraction which leads to energy expenditure beyond resting level (Ryan, et al., 2017).

The early epidemiological studies demonstrated a clear dose-response relationship between physical activity (PA) and the risks for all-cause mortality with the least physically active individual having the highest risk (Ryan et al, 2017). On a similar note, Warburton (2010) compared relative risk reduction of active and inactive individuals and the author's report was as follows; $31 \%$ risk reduction and $45 \%$ if aerobic fitness is assessed for premature all-cause mortality, 33\% reduction in the risk of cardiovascular disease, $31 \%$ risk reduction for stroke, $50 \%$ risk reduction for hypertension if aerobic fitness is assessed, $30 \%$ risk reduction for colon cancer, $20 \%$ reduction for breast cancer, $40 \%$ risk reduction was set for Type 2 diabetes and improved bone health was assured if routine physical activity is performed.

These figures simply indicate that for every regular participation in PA, there is a large reduction in risk of non-communicable diseases (NCDs). Contrarily, World Health Organisation (2018) non-communicable disease country profile for Nigeria reported that; NCDs accounted for $29 \%$ of all deaths and physical inactivity related deaths was set at $22 \%$ for males and $27 \%$ for females aged 18 years and above. A similar study by Adewale, et al., (2018) also reported that physical inactivity related non-communicable diseases were responsible for about 3 million deaths in sub-Saharan Africa, a region where Nigeria belongs. It was also suggested in the study that these deaths will increase up to $80 \%$ if appropriate actions are not taken. In Nigeria, physical activity related non-communicable disease is responsible for at least one quarter and one third of all deaths in males and females respectively (Abegunde, et al., 2007; WHO, 2014). This revelation is worrisome, because, despite the various campaigns and sensitisation programmes on the dangers of physical inactivity, the situation has continued to worsen based on the figures in these reports.

The major causes of death and diseases in our society are related to lifestyle choices and achieving wellness requires that an individual makes lifestyle choices that will reduce disease risk factors and promote health. These choices include being physically active on regular basis, taking time for relaxation and managing stress effectively (Wuest \& Bucher, 2006). Conversely, physical inactivity and sedentary living have been identified as major independent modifiable risk factors for chronic diseases, the fourth leading risk factor for global mortality associated with mental health injuries, falls and obesity (WHO, 2009).

There are international guidelines and recommendations for physical activity participation and majority of these bodies or organisations set a minimum of 150 
minutes of moderate intensity physical activity involvement weekly to confer health benefits to the participants. Surprisingly, WHO (2018a) estimates that up to $60 \%$ of the global population fail to complete the recommended amount of PA required to induce health benefits. In Africa, Kolbe-Alexander, Draper and Lambert (2010), Observed that there are indications of high levels of physical inactivity among adults and children.

According to Quintiliani (2008), stated that workplace offers several advantages for promoting physical activity because a substantial number of the workforce can be reached and multiple levels of influence on behaviour can be targeted. Civil servants constitute a large percentage of a nation's workforce and majority of them are at high risk of obesity due to the lifestyle of physical inactivity (Isaac et al, 2017). Considering the key role played by the civil servants in the economy of a nation, it will be highly risky to ignore them as physical inactivity could lead to consortium of diseases which will ultimately affect their health leading to absenteeism from work, low productivity and ultimately take a toll on the nation's economy.

In workplaces, researchers have identified certain factors which influence participation in regular PA. These factors include knowledge of about PA, job satisfaction, occupational demand and provision of sport facilities and equipment (Omolawon \& Sanusi, 2006; Olorunsola, 2012). Similarly, lack of time due to responsibilities related to family and environment and level of awareness of PA benefits accounts for low participation in PA among the working population. (Daskapan, 2006; Umeifekwem, 2011). Akindutire and Adegboyega (2012) reported that chronic diseases associated with inactivity and sedentary living are on the increase in workplaces, and suggested the need to gain better insight into the dynamics of PA pattern and behaviour in such environments. Improving physical activity level is one of the golden strategies for controlling physical inactivity related communicable disease (Pratt, et al., 2015), however, for positive PA behaviour to be effectively promoted and entrenched among diverse working population, researchbased evidence on staff knowledge of physical activity and their patterns has to be given attention. To our knowledge, no study has been conducted on physical activity pattern of the study population. Hence, the need for this study.

\section{METHOD}

The population for this study comprised all the five hundred and eighteen (518) Civil Servants in Ilorin South Local Government in the Ministry of works and Transport, Civil service Commission and Teaching service commission in Kwara State, Nigeria. Stratified sampling was conducted to classify the ministries into three namely; Ministry of works and Transport, Civil service Commission and Teaching service commission. Proportionate sampling method was used to select fifty per cent $(50 \%)$ of the workers across the ministries. Finally, simple probability sampling technique was conducted to select two hundred and fifty-nine (259) respondents which formed the sample for this study. However, five (5) questionnaires were not retrieved during data collection. Therefore, a total of two hundred and fifty-four (254) questionnaires were retrieved and used for analysis. Adapted global physical activity questionnaire (GPAQ) was used to collect data for this study. The questionnaire was validated by experts in the related field and was 
tested for reliability using Pearson's product moment correlation (PPMC); it was found reliable at 0.84 . Informed consent of the respondents was obtained and the questionnaire were then distributed among the study participants and retrieved after completing it. The socio-demographic data was analysed with descriptive statistics and inferential statistics of independent samples t-test, PPMC and analysis of variance (ANOVA) were used to test the null hypotheses. The significance level was set at 0.05 alpha.

\section{RESULT AND DISCUSSION}

\section{Result}

Table 1. Demographic Characteristics of Civil Servants in Ilorin South Local Government Area of

\begin{tabular}{|c|c|c|c|}
\hline \multicolumn{4}{|c|}{ Kwara State } \\
\hline \multicolumn{2}{|c|}{ Variables } & Frequency & Percentage \\
\hline \multirow{10}{*}{ Age Range } & $18-22$ yrs. & 51 & 20.1 \\
\hline & $23-27$ yrs. & 71 & 28.0 \\
\hline & $31-35$ yrs. & 36 & 14.2 \\
\hline & $36-40$ yrs. & 24 & 9.4 \\
\hline & $41-45$ yrs. & 8 & 3.1 \\
\hline & $46-50$ yrs. & 21 & 8.3 \\
\hline & $51-55$ yrs. & 13 & 5.1 \\
\hline & $56-60$ yrs. & 14 & 5.5 \\
\hline & $61-65$ yrs. & 16 & 6.3 \\
\hline & Total & 254 & 100.0 \\
\hline \multirow{3}{*}{ Gender } & Male & 130 & 51.2 \\
\hline & Female & 124 & 48.8 \\
\hline & Total & 254 & 100.0 \\
\hline \multirow{5}{*}{ Ministry/Commission } & $\begin{array}{l}\text { Civil Service } \\
\text { Commission }\end{array}$ & 48 & 18.9 \\
\hline & Works & 138 & 54.3 \\
\hline & Teaching Service & & \\
\hline & Commission & 68 & 26.8 \\
\hline & Total & 254 & 100.0 \\
\hline \multirow{6}{*}{ Marital Status } & Single & 86 & 33.9 \\
\hline & Married & 143 & 56.3 \\
\hline & Widow & 12 & 4.7 \\
\hline & Divorced & 9 & 3.5 \\
\hline & Separated & 4 & 1.6 \\
\hline & Total & 254 & 100.0 \\
\hline \multirow{6}{*}{$\begin{array}{l}\text { Educational } \\
\text { Qualification }\end{array}$} & O'level & 12 & 4.7 \\
\hline & $\mathrm{ND} / \mathrm{NCE}$ & 82 & 32.3 \\
\hline & B.Sc/HND & 117 & 46.1 \\
\hline & Master & 36 & 14.2 \\
\hline & Ph.D & 7 & 2.8 \\
\hline & Total & 254 & 100.0 \\
\hline
\end{tabular}

Table 1 shows demographic characteristics of the respondents in this study ( $\mathrm{n}$ $=254$ ) who are civil servants in Ilorin South Local Government of Kwara State. Result for age indicate that majority of them $71(28.0 \%)$ are within the age range of $23-27$ years, the next to this group are $51(20.1 \%)$ of them who are within the age range of $23-27$ years and the fewest age group is $8(3.1 \%)$ of them within the age range of 41 - 45 years. For gender, the result shows majority of them $130(51.2 \%)$ are male and rest of them 124 (48.8) are females. The result indicates that majority 
of the civil servants $138(54.3 \%)$ work in the Ministry of Works, 68 (26.8\%) of them work in the Teaching Service Commission and the remaining $48(18.9 \%)$ of them work in the Civil Service Commission. For marital status, it was revealed that majority of them 143 (56.3\%) are married, 86 (33.9\%) of them are single, 12 (4.7\%) of them are widowed, $9(3.5 \%)$ of them are divorced and $4(1.6 \%)$ of them are separated. Result for their qualification reveals that majority $117(46.1 \%)$ of them are B.Sc./HND holders, 82 (32.3\%) are NCE holders, 36 (14.2\%) of them are Master holders, 12 (4.7\%) of them are 0'level holders and 7 (2.8\%) Ph.D. holders.

Table 2. Physical Activity Knowledge of Civil Servants in Ilorin South Local Government Area of Kwara State

\begin{tabular}{|c|c|c|c|c|}
\hline $\mathbf{S} / \mathbf{N}$ & $\begin{array}{c}\text { Variables of Physical Activity } \\
\text { Knowledge }\end{array}$ & Response & Frequency & Percentage \\
\hline \multirow{6}{*}{1.} & \multirow{5}{*}{$\begin{array}{l}\text { Duration of Physical Activity } \\
\text { Required weekly }\end{array}$} & 150 minutes & 51 & 20.1 \\
\hline & & 160 minutes & 65 & 25.6 \\
\hline & & 180 minutes & 75 & 29.5 \\
\hline & & 200 minutes & 15 & 5.9 \\
\hline & & 220 minutes and above & 48 & 18.9 \\
\hline & Total & & 254 & 100.0 \\
\hline \multirow{6}{*}{2.} & \multirow{5}{*}{$\begin{array}{l}\text { Sufficient Physical Activity for } \\
\text { Health Benefits in Adults }\end{array}$} & $\begin{array}{l}30 \text { minutes of vigorous } \\
\text { intensity PA at least } 2 \\
\text { days per week }\end{array}$ & 45 & 17.7 \\
\hline & & $\begin{array}{l}30 \text { minute of moderate } \\
\text { intensity PA on } 5 \text { or } \\
\text { more days per week }\end{array}$ & 86 & 33.9 \\
\hline & & 40 minutes & 53 & 20.9 \\
\hline & & 50 minutes & 10 & 3.9 \\
\hline & & 1 hour and above & 60 & 23.6 \\
\hline & Total & & 254 & 100.0 \\
\hline \multirow{6}{*}{3.} & \multirow{5}{*}{$\begin{array}{l}\text { Sufficient Physical Activity for } \\
\text { Health Benefits in Youths }\end{array}$} & $\begin{array}{l}30 \text { minutes of vigorous } \\
\text { intensity PA at least } 2 \\
\text { days per week }\end{array}$ & 49 & 19.3 \\
\hline & & $\begin{array}{l}30 \text { minute of moderate } \\
\text { intensity PA on } 5 \text { or } \\
\text { more days per week }\end{array}$ & 65 & 25.6 \\
\hline & & 40 minutes & 19 & 7.5 \\
\hline & & 50 minutes & 18 & 7.1 \\
\hline & & 1 hour and above & 103 & 40.6 \\
\hline & Total & & 254 & 100.0 \\
\hline \multirow{6}{*}{4.} & \multirow{5}{*}{$\begin{array}{l}\text { Sufficient Repetition of Physical } \\
\text { Activity for an Individual Daily }\end{array}$} & 3 repetitions & 72 & 28.3 \\
\hline & & 4 repetitions & 65 & 25.6 \\
\hline & & 5 repetitions & 41 & 16.1 \\
\hline & & 6 repetitions & 20 & 7.9 \\
\hline & & 7 repetitions and above & 56 & 22.0 \\
\hline & Total & & 254 & 100.0 \\
\hline \multirow{6}{*}{5.} & \multirow{6}{*}{$\begin{array}{l}\text { Type of Physical Activity Individuals } \\
\text { should Engage in }\end{array}$} & Jogging & 85 & 33.5 \\
\hline & & Walking & 68 & 26.8 \\
\hline & & Cycling & 35 & 13.8 \\
\hline & & Running & 44 & 17.3 \\
\hline & & Brisk Walking & 22 & 8.7 \\
\hline & & & 254 & 100.0 \\
\hline
\end{tabular}

Table 2 shows result of descriptive analysis of physical activity knowledge of civil servants in Ilorin South Local Government, Area of Kwara State. Their knowledge on minimum duration of physical activity requirement per week is not 
adequate as only $51(20.1 \%)$ selected the correct option of 150 minutes while the rest selected wrong options. Majority of them 75 (29.5\%) selected 180 minutes per week, 65 (25.6\%) of them selected 160 minutes, $48(18.9 \%)$ of them selected 220 minutes and the remaining 15 (5.9\%) of them selected 200 minutes.

Table 3. Physical Activity Pattern of Civil Servants in Ilorin South Local Government Area of Kwara

\begin{tabular}{|c|c|c|c|c|}
\hline \multicolumn{5}{|c|}{ State } \\
\hline $\mathbf{S} / \mathbf{N}$ & $\begin{array}{c}\text { Variables of Physical Activity } \\
\text { Knowledge }\end{array}$ & Response & Frequency & Percentage \\
\hline \multirow{7}{*}{1.} & \multirow{6}{*}{$\begin{array}{l}\text { How often engage in physical } \\
\text { activity per week }\end{array}$} & Every day of the week & 42 & 16.5 \\
\hline & & 3 time per week & 65 & 25.6 \\
\hline & & 2-3 time per week & 19 & 7.5 \\
\hline & & 2 times per week & 43 & 16.9 \\
\hline & & 1-2 time per week & 56 & 22.0 \\
\hline & & Not at all & 29 & 11.4 \\
\hline & Total & & 254 & 100.0 \\
\hline \multirow{6}{*}{2.} & \multirow{5}{*}{$\begin{array}{l}\text { Time spent participating in } \\
\text { physical activities }\end{array}$} & Less than 20 minutes & 77 & 30.3 \\
\hline & & 20-30 minutes & 76 & 29.9 \\
\hline & & 40-50 minutes & 33 & 13.0 \\
\hline & & 50-60 minutes & 12 & 4.7 \\
\hline & & 1 hour and above & 56 & 22.0 \\
\hline & Total & & 254 & 100.0 \\
\hline \multirow{6}{*}{3.} & \multirow{5}{*}{ Regular means of transportation } & Trekking & 39 & 15.4 \\
\hline & & Bicycle & 35 & 13.8 \\
\hline & & Motor cycle & 57 & 22.4 \\
\hline & & Car & 119 & 46.6 \\
\hline & & Other & 4 & 1.6 \\
\hline & Total & & 254 & 100.0 \\
\hline \multirow{6}{*}{4.} & \multirow{5}{*}{$\begin{array}{l}\text { Confident to be in physical activity } \\
\text { next three month }\end{array}$} & Confident & 66 & 26.0 \\
\hline & & High Confident & 97 & 38.2 \\
\hline & & Extremely Confident & 69 & 272 \\
\hline & & No Confident & 20 & \\
\hline & & 5 & 2 & $\begin{array}{l}7.9 \\
8\end{array}$ \\
\hline & Total & & 254 & 100.0 \\
\hline \multirow{6}{*}{5.} & \multirow{5}{*}{$\begin{array}{l}\text { Regular engagement in physical } \\
\text { activity to minimise stress }\end{array}$} & Never & 37 & 14.6 \\
\hline & & Seldom (1-2days) & 109 & 42.9 \\
\hline & & Sometimes (3-4days) & 74 & 31.1 \\
\hline & & Often (5-7days) & 24 & 9.4 \\
\hline & & 5 & 5 & 2.0 \\
\hline & Total & & 254 & 100.0 \\
\hline \multirow{7}{*}{6.} & \multirow{6}{*}{$\begin{array}{l}\text { Time spent while sitting in a } \\
\text { weekday }\end{array}$} & Less than 20 minutes & & \\
\hline & & & 83 & 32.7 \\
\hline & & 20-30 minutes & 79 & 31.1 \\
\hline & & 40-50 minutes & 31 & 12.2 \\
\hline & & 50-60 minutes & 26 & 10.2 \\
\hline & & 1 hour and above & 35 & 13.8 \\
\hline & Total & & 254 & 100.0 \\
\hline
\end{tabular}

Table 3 shows result of descriptive analysis of physical activity pattern of civil servants in Ilorin South Local Government, Area of Kwara State. Their pattern on physical activity per week, Majority of them selected 3 times per week, 65 (25.6\%) while the rest selected as followed 1-2 times per week, 56 (22.0.5\%), of them selected 2 times per week, 43 (16.9\%) of them selected every day, 42 (16.5\%) of 
them selected not at all, $29(11.4)$ and the remaining $19(7.5 \%)$ of them selected 23 times per week.

Table 4: Screen-Based Activity for Civil Servants in Ilorin South Local Government Area of Kwara State

\begin{tabular}{|c|c|c|c|c|}
\hline $\mathbf{S} / \mathbf{N}$ & $\begin{array}{c}\text { Variables of Physical Activity } \\
\text { Knowledge }\end{array}$ & Response & Frequency & Percentage \\
\hline \multirow{6}{*}{1.} & \multirow{5}{*}{$\begin{array}{l}\text { How many Hours spend watching } \\
\text { TV per day }\end{array}$} & Not at all & 1 & .4 \\
\hline & & Less than 1 hour & 39 & 15.4 \\
\hline & & 1 hour & 73 & 28.7 \\
\hline & & 2-3 hours & 94 & 37.0 \\
\hline & & 4 hours and above & 47 & 18.5 \\
\hline \multirow{2}{*}{\multicolumn{2}{|c|}{ Total }} & & 254 & 100.0 \\
\hline & & Less than 1 hour & 33 & 13.0 \\
\hline \multirow[t]{4}{*}{2.} & \multirow{3}{*}{$\begin{array}{l}\text { How many Hours spend on smart } \\
\text { phone per day }\end{array}$} & 1 hour & 48 & 18.9 \\
\hline & & 2-3 hours & 94 & 37.0 \\
\hline & & 4 hours and above & 79 & 31.1 \\
\hline & Total & & 254 & 100.0 \\
\hline \multirow{6}{*}{3.} & \multirow{4}{*}{$\begin{array}{l}\text { How many Hours do you spend on } \\
\text { computer system daily }\end{array}$} & Less than 1 hours & 80 & 31.5 \\
\hline & & 1 hour & 50 & 19.7 \\
\hline & & 2-3 hours & 88 & 34.6 \\
\hline & & 4 hours and above & 34 & 13.4 \\
\hline & \multirow[b]{2}{*}{ Total } & Not at all & 1 & .4 \\
\hline & & & 254 & 100.0 \\
\hline \multirow{6}{*}{4.} & \multirow{5}{*}{$\begin{array}{l}\text { How many Hours spend on } \\
\text { playing computer game per day }\end{array}$} & Less than 1 hour & 65 & 25.6 \\
\hline & & 1 hour & 47 & 18.5 \\
\hline & & 2-3 hours & 30 & 11.8 \\
\hline & & 4 hours and above & 20 & 7.9 \\
\hline & & Not at all & 92 & 36.2 \\
\hline & Total & & 254 & 100.0 \\
\hline
\end{tabular}

Table 4 shows result of descriptive analysis of screen-based activity of civil servants in Ilorin South Local Government, Area of Kwara State. Their sedentary life choice after working hour as only $1(.4 \%)$ selected not engaged in screen-based activity, Majority of them selected 2-3 hours, 94 (37.0\%) while the rest selected as follows; 1 hour, 73 (28.7\%), of them selected 4 hours and above, 47 (18.5\%) of them selected less than hour, 39 (15.4\%).

Table 5: Pearson Correlation Showing the Relationship between Knowledge and Pattern of Physical Activity among Civil Servants in Ilorin South Local Government of Kwara State

\begin{tabular}{lllllll}
\hline \multicolumn{1}{c}{ S/N } & \multicolumn{1}{c}{ Variables } & $\mathbf{N}$ & $\mathbf{d f}$ & $\mathbf{r}$ & $\mathbf{S i g}$ & $\mathbf{r}^{\mathbf{2}}$ \\
\hline 1. & Knowledge of Physical Activity & & & & & \\
2. & Physical Activity Pattern & & 254 & .191 & .002 & .036
\end{tabular}

$\mathrm{p} \leq 0.05$

Table 5 shows PPMC analysis of the relationship between physical activity knowledge and physical activity pattern of civil servants in Ilorin South Local Government of Kwara State $(n=254)$. The result reveals a significant low positive relationship between their knowledge of physical activity and their pattern of physical activity participation $\mathrm{r}(252)=.191, \mathrm{p}<.002$. The level of significance (Sig.) for this result is within the set alpha level of $\mathrm{p} \leq 0.05$. Therefore, the tested null 
hypothesis is rejected. The result had a coefficient of determination (r2) 0.36 , which indicates that the respondent knowledge of physical activity accounts for only $3.6 \%$ variation in physical activity pattern. This implies that due to the participants' poor knowledge of physical activity it contributes very little to their participation in physical activity.

Table 6: One-Way ANOVA for Influence of Age on Knowledge and Pattern of Physical Activity among Civil servants in Ilorin South Local Government Area of Kwara State

\begin{tabular}{llrrrrr}
\hline Variables & & \multicolumn{1}{c}{$\begin{array}{c}\text { Sum of } \\
\text { Squares }\end{array}$} & df & $\begin{array}{c}\text { Mean } \\
\text { Square }\end{array}$ & F & Sig. \\
\hline Knowledge of Physical & Between Groups & 351.348 & 8 & 43.919 & 2.139 & .033 \\
Activity & Within Groups & 5031.191 & 245 & 20.535 & & \\
& Total & $\mathbf{5 3 8 2 . 5 3 9}$ & $\mathbf{2 5 3}$ & & & \\
& Between Groups & 174.581 & 8 & 21.823 & 1.099 & .364 \\
Pattern of Physical & Within Groups & 4845.095 & 244 & 19.857 & & \\
Activity & Total & $\mathbf{5 0 1 9 . 6 7 6}$ & $\mathbf{2 5 2}$ & & & \\
\hline
\end{tabular}

$\mathrm{p} \leq 0.05$

Table 6 shows the result of one-way ANOVA for the influence of age on physical activity knowledge and pattern of physical activity among civil servants in Ilorin South Local Government of Kwara State $(n=254)$. The result indicated that there is a significant difference in their knowledge due to age variations $F(8,245)=2.139$, $\mathrm{p}<.033$ and no significant difference in their physical activity pattern due to their age variations $F(8,252),=1.099 p<.364$.

Table 7.t-test Analysis Showing Influence of Gender on Knowledge and Pattern of Physical Activity among Civil Servants in Ilorin South Local Government of Kwara State

\begin{tabular}{llllccccc}
\hline \multicolumn{1}{c}{ Variables } & Gender & N & Mean & $\begin{array}{c}\text { Std. } \\
\text { Deviation }\end{array}$ & $\begin{array}{c}\text { Mean } \\
\text { Diff }\end{array}$ & T & Df & Sig \\
\hline Knowledge of & Male & 130 & 17.085 & 4.592 & & & & \\
Physical Activity & Female & 124 & 16.710 & 4.643 & .375 & .647 & 252 & .518 \\
Pattern of Physical & Male & 129 & 27.217 & 4.541 & & & & \\
Activity & Female & 124 & 26.540 & 4.372 & .677 & 1.207 & 252 & .229 \\
\hline
\end{tabular}

$\mathrm{p} \leq 0.05$

Table 7 shows result of t-test analysis for the influence of gender on physical activity knowledge and physical activity pattern of civil servants in Ilorin South Local Government Area of Kwara State $(n=254)$. The result indicates average knowledge of Mean 17.085, SD 4.592 for male $(n=130)$ and Mean 16.710, SD 4.643 for female; which reveals no significant difference in physical activity knowledge between male and female $t(252)=.647, p>.518$. On average the score of physical activity pattern of male is Mean 27.217, SD 4.541and that of female is Mean 26.540, SD 4.372; this showed no significant difference between physical activity pattern of male and female $t(252)=1.207, p>.229$. Based on this, the tested null hypothesis is not rejected. 
Table 8: One-Way ANOVA for Influence of Work Environment on Knowledge and Pattern of Physical Activity among Civil servants in Ilorin South Local Government Area of Kwara State

\begin{tabular}{llrrrrr}
\hline Variables & \multicolumn{1}{c}{$\begin{array}{c}\text { Sum of } \\
\text { Squares }\end{array}$} & df & $\begin{array}{c}\text { Mean of } \\
\text { Squares }\end{array}$ & \multicolumn{1}{c}{ F } & \multicolumn{1}{c}{ Sig. } \\
\hline Knowledge of & Between Groups & 10.085 & 2 & 5.042 & .236 & .790 \\
Physical Activity & Within Groups & 5372.455 & 251 & 21.404 & & \\
& Total & $\mathbf{5 3 8 2 . 5 3 9}$ & $\mathbf{2 5 3}$ & & & \\
Pattern of & Between Groups & 92.993 & 2 & 46.496 & 2.359 & .097 \\
Physical Activity & Within Groups & 4926.683 & 250 & 19.707 & & \\
& Total & $\mathbf{5 0 1 9 . 6 7 6}$ & $\mathbf{2 5 2}$ & & & \\
\hline
\end{tabular}

Table 7 shows the result of one-way ANOVA for the influence of work environment on physical activity knowledge and pattern of physical activity among civil servants in Ilorin South Local Government, Area of Kwara State ( $n=254)$. The result indicated that there is no significant difference in their knowledge due to work of environment variations $F(2,253)=.236, p<.790$ and no significant difference in their physical activity pattern due to their work of environment variations $F(2,252),=2.359 \mathrm{p}<.097$. Based on this, the tested null hypothesis is not rejected.

Table 9: One-Way ANOVA for Influence of Marital status on Knowledge and Pattern of Physical Activity among Civil servants in Ilorin South Local Government Area of Kwara State

\begin{tabular}{llccccc}
\hline \multirow{2}{*}{ Variables } & & $\begin{array}{c}\text { Sum of } \\
\text { Squares }\end{array}$ & Df & Sig. & F & Sig. \\
\hline \multirow{2}{*}{ Knowledge of } & Between Groups & 58.552 & 4 & 14.638 & .685 & .603 \\
Physical Activity & Within Groups & 5323.987 & 249 & 21.381 & & \\
& Total & $\mathbf{5 3 8 2 . 5 3 9}$ & $\mathbf{2 5 3}$ & & & \\
Pattern & Between Groups & 60.521 & 4 & 15.130 & .757 & .554 \\
Physical Activity & Within Groups & 4959.155 & 248 & 19.997 & & \\
& Total & $\mathbf{5 0 1 9 . 6 7 6}$ & $\mathbf{2 5 2}$ & & & \\
\hline
\end{tabular}

Table 9 shows the result of one-way ANOVA for the influence of marital Status on physical activity knowledge and pattern of physical activity among civil servants in Ilorin South Local Government, Area of Kwara State $(n=254)$. The result indicated that there is no significant difference in their knowledge due to marital status variations $F(4,253)=.685, \mathrm{p}<.603$ and no significant difference in their physical activity pattern due to their marital status variations $F(2,252),=.757 \mathrm{p}<.554$. Based on this, the tested null hypothesis was retained.

\section{Discussion of Findings}

This study was conducted to assess the Knowledge and Pattern of Physical Activity of Civil Servants in Ilorin South Local Government, Area of Kwara State. Two hundred and sixty samples participated in the study and five research hypotheses were postulated for the study.

Hypothesis one revealed that there is a significant relationship between knowledge and pattern of physical activity of civil servants in Ilorin West Local Government of Kwara State. This finding supports the assertion of Arobonlo (2007), moderate amount of physical activities can be achieved in a variety of ways. People can select activities that they enjoy and that fit into their lives. He recommended that Nigerians should avail themselves of the numerous cheap and easy to perform 
physical activities: such as jogging, walking, brisk walking, continuous running, cycling among others to keep obesity and overweight under check. The report of WHO (2003), on aerobic activity should be performed in episode of at least 10 minutes, and preferably, it should be spread through the week. For additional and more extensive benefits, adults should increase their aerobic physical activity to 30 minutes (5 hours) a week of moderate-intensity, or 150 minutes a week of vigorousintensity aerobic physical activity, or an equivalent combination of moderate and vigorous-intensity aerobic activity. Moderate physical activities lasting for at least 30 minutes for most days of the week is recommended.

Hypothesis two revealed that there is a significant difference in their knowledge due to age variations and no significant difference in their physical activity pattern due to their age variations. This finding supports the assertion of Arongbonlo (2007), four out of five people who die from coronary heart disease are aged 65 or older. The risk of stroke doubles with each decade after the age of 55 . Arongbonlo (2007) further added that death rate of women from heart disease and stroke is twice as high as those for all forms of cancer. The risk for women increases as they approach menopause and continues to rise as they get older, possibly due to the loss of the natural hormone oestrogen. WHO (2003) Physical activity is beneficial to people of all ages and of different sex. However, there are some barriers that are against people's full participation in physical activities to improve their health and fitness.

Hypothesis three revealed that there is no significant difference in physical activity knowledge between male and female and no significant difference between physical activity pattern of male and female. This finding supports the assertion of Myers et al (2002), reported in a study on physical activity capacity and mortality among men referred for physical activity testing that men who were sedentary were 4 times more likely to die than men with regular physical activity capacity. This was true for men with and without cardiovascular disease, suggesting that physical activity capacity may even offset some of the risks associated with cardiovascular diseases. As physical activity capacity decreased the risk of death increased in males. WHO (2005), reports on women and physical activities has it that regular physical activities and good eating habits can improve women's health and prevent many of the diseases and conditions that are major causes of death and disability for women around the world. It also added that regular physical activities helps reduce stress, anxiety, depression and loneliness, this is particularly important for women as rates of depression for women almost double those of men in developed countries. Physical activities also help build self-esteem, confidence, promote psychological wellbeing and social integration in women.

Hypothesis four revealed that there is no significant difference in their knowledge due to work of environment variations and no significant difference in their physical activity pattern due to their work of environment variations. This finding supports the assertion of Roemmich (2008) increased access to reinforcing sedentary behaviours within the home increases time people allocate for watching television. Thus, people may be more likely to stay home and be sedentary if watching television or other sedentary activities are more accessible and more reinforcing than physical activity, (Roemmich, et al. 2004). Conversely, if people live in a community with more sidewalks, greater number of parks and more connecting 
streets this greater access to physical activity may positively impact of people participation in physical activity. Such studies not only take into consideration the characteristics of individuals, but also those of the environment in which they live. Even more recently studies have been carried out into the influence of the physical environment. In the literature the concept of physical environment has been defined as the existence of and physical accessibility to centre such as gyms, swimming pools and leisure centre's informal spaces that form part of a neighbourhood's facilities such as open public spaces, and the layout and use of buildings; or aspects regarding traffic, safety and attractiveness of neighbourhoods and local areas (Ewing, 2005).

Hypothesis five revealed that there is no significant difference in their knowledge due to marital status variations and no significant difference in their physical activity pattern due to their marital status variations. These findings are also supported by the (Koeneman, et al, 2011) review on determinants of participation in physical activity and physical activity. Another demographic determinant of participating in health promotion activity is marital status as identified by (Pender et al, 2002). Regular participation in physical activity can prolong health by offsetting the development of chronic diseases and conditions, however, many older adults are inactive (Dipietro, 2001). The Health, Aging, and Body Composition (Health ABC) study offers a distinct opportunity to explore the relationship between marital status and physical activity, not only using the entire cohort, but specifically through a sub group of married couples that were enrolled together in the study. In Health $\mathrm{ABC}$, both physical activity and non-physical activity were measured, providing an estimate of total physical activity participation. Furthermore, for some participants, both members of the spousal pair underwent the same enrolment procedures and all measured variables were assessed using the same methods. This provides the unique opportunity to examine the relationship of physical activity participation in individual members of a married couple and contrasts previous work where spousal pair data were collected by proxy from a single member of the married couple, (Schone \& Weinick, 2005). Moreover, a notable relationship between members of a married couple may suggest a novel approach to utilize when attempting to increase physical activity levels in older individuals.

\section{CONCLUSION}

Based on the findings of the study, following conclusions were drawn. There is significant relationship on Knowledge and Pattern of Physical Activity of Civil Servants in Ilorin South Local Government Kwara State. There was significant difference on the Knowledge and Pattern of Physical Activity based on age of Civil Servants in Ilorin South Local Government, Kwara State. There was no significant difference on the Knowledge and Pattern of Physical Activity based on gender of Civil Servants in Ilorin South Local Government, Kwara State. There was no significant difference on the Knowledge and Pattern of Physical Activity based on working environment of Civil Servants in Ilorin South Local Government, Kwara State. There was no significant difference on the Knowledge and Pattern of Physical Activity based on marital status of Civil Servants in Ilorin South Local Government, Kwara State. 
Based on the conclusion, the following recommendations were made: 1) Experts in the field of physical activity and fitness in conjunction with the management of various ministries and commissions should organise workshops and seminar to improve the knowledge of the civil servants on the benefits of regular participation in physical activity, 2) Gender, marital status and educational qualifications should be considered while planning physical activity intervention for the workers, 3) Management of various ministries and commissions should create an official hour for all the staff to participate in physical activities such as jogging, trekking and brisk walking.

\section{ACKNOWLEDGEMENT}

This study was not receive any support. There is no conflict of interest in this study.

\section{REFERENCES}

Abegunde, D.O, Mathers C.D, Adam, T, Ortegon,M, Strong, K. The burden and costs of chronic diseases in low-income and middle-income countries. Lancet. 2007; 370(9603): 1929-38.

Adewale, L. O, Adetoyeje,Y. O, Babatunji, A. O, Aliyu, L, Kingsley, K. A, Rufus, A. Andrea, R. (2018). Physical activity profile of Nigeria: implications for research, surveillance and $\begin{array}{llll}\text { policy. The Pan African Medical Journal.; } & \text { 30:175. }\end{array}$ doi:10.11604/pamj.2018.30.175.12679

Arongbonlo, S. (2007). The Rescue Mission of Physical Activities to Heart Conditions and Related Health Problems among the Nigerian populace. Journal of sports management and educational Research, 1(3).

Dipietro, L. Physical activity in aging: changes in patterns and their relationship to healthy and function. Journal of Gerentolology A: Biol. Sci.Med. Sci. 56A:12-22, 2001.

Isaac, A, Oladele, V. A, Olufunmilayo, F. M, Daniel, T. G, Anthony, I. A. \& Eyitayo, O.O. (2017). Pattern and correlates of obesity among public service workers in Ondo State, Nigeria: a cross-sectional study, South African Family Practice, 59:6, 195-200, DOI: 10.1080/20786190.2017.1333784

Pratt M, Ramirez, A, Martins, R, Bauman A, Heath, G, Kohl 3rd H, et al. 127 Steps toward a more active World. Journal of Physical Activity and Health; 12(9): 1193-4.

Psychology \& Health, 32:8, 942-975, DOI: 10.1080/08870446.2017.1325486

Quintiliani, Sattelmair \& Sorensen (2008), The workplace offers several advantages for promoting physical activity in that a substantial number of the working population can be reached and multiple levels of influence on behaviour can be targeted review of the evidence for Canada's physical activity guidelines for adults. International Journal of Behavioural Nutrition and Physical Activity, 7, 39. doi:10.1186/1479-58687-39

Roemmich et al., 2007; people live in a community with more sidewalks, greater number of parks and more connecting streets this greater access to physical activity may positively impact of people participation in physical activity Sci.Med. Sci. 56A:12-22, 2001.

Ryan E. Rhodes, Ian Janssen, Shannon S.D. Bredin, Darren E.R. Warburton \& Adrian Bauman (2017). Physical activity: Health impact, prevalence, correlates and interventions, 
United Nations, Department of Economic and Social Affairs, Population Division (2015). World Population Prospects: The 2015 Revision, Key Findings and Advance Tables. Working Paper No. ESA/P/WP.241

Warburton, D. E. R., Taunton, J., Bredin, S. S. D., \& Isserow, S. (2016). The risk-benefit paradox of exercise. BC Medical Association Journal, 58, 210-218.

Warburton, D. E., Charlesworth, S., Ivey, A., Nettlefold, L., \& Bredin, S. S. (2010). A systematic

WHO Press. World Health Organization, (2012). "Young and physically active: A blueprint for making physical activity appealing to youth." In.http://www.euro.who.into/ data/assets/PDF file/0005/175325/e96697.pdf?UA=1.

World Health Organization - Noncommunicable Diseases (NCD) Country Profiles, 2018.

World Health Organization (2014) Global Status Report on non-communicable disease 2014. Geneva: World Health Organization (WHO) (2010). Global recommendations on physical activity for health. Geneval, Switzerland:

World Health Organization (2014) Global Status Report on non-communicable disease 2014. Geneva: World Health Organization (WHO).

World Health Organization (2014). Global status report on noncommunicable diseases Geneva.;Switzerland. World Health Organization. Global status report on noncommunicable diseases 2014, Geneva.

Wuest, D.A. and Butcher, C.A. (2006). Foundations of physical Education, Physical activity Science, and Sport 16th Ed. McGraw Hill Boston pp.21-23.

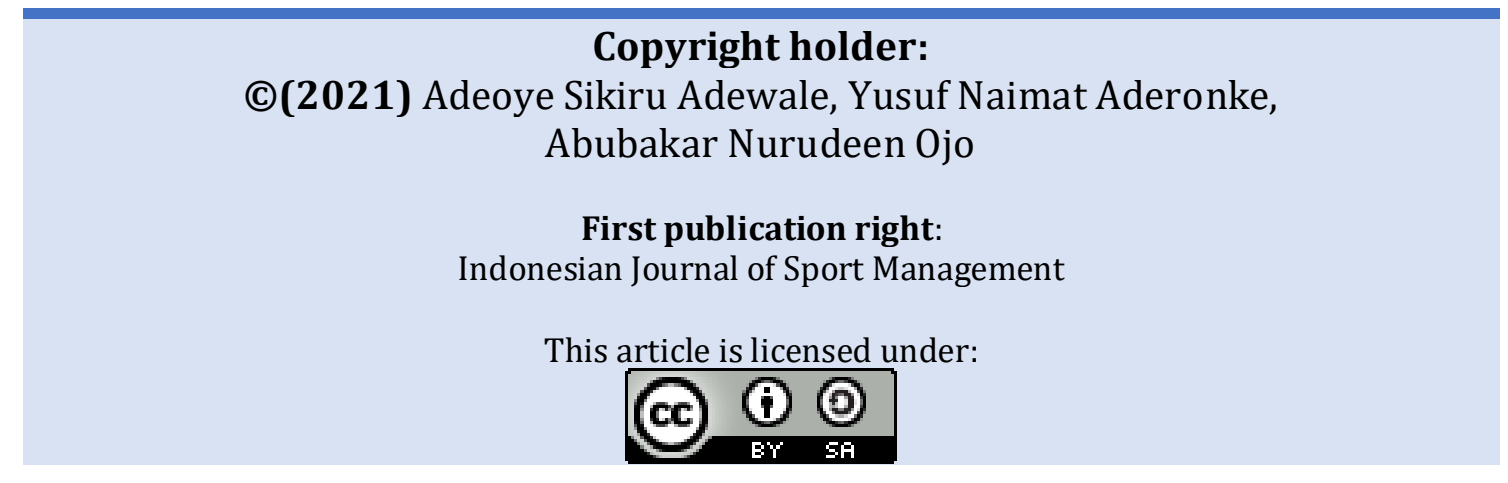

